\title{
Sobre pontes, fronteiras e abismos
}

\section{Daniele Avila Small}

Em Março de 2008, inauguramos a Questão de crítica, revista eletrônica de críticas e estudos teatrais, no endereço www.questaodecritica.com.br, sediada no Rio de Janeiro, mas com o olhar voltado para a produção teatral contemporânea, independentemente dos nossos limites geográficos. Desde então, tentamos ao máximo comparecer a espetáculos de outras cidades em visita ao Rio, procurando, sempre que possivel, estender o nosso olhar para além das fronteiras da chamada cidade maravilhosa. 0 fato de que fazemos a revista exclusivamente com recursos próprios nesses primeiros quatro anos de trajetória não nos permite viajar como gostaríamos, mas a Internet nos faz acreditar que não estamos tão circunscritos à produção local. As estatísticas de visitação do site também nos mostram que nossos leitores não são apenas os nossos vizinhos.

Publicamos edições mensais, com textos distribuidos em cinco seções: críticas, estudos, conversas, processos e traduções. A seção de críticas é o carro-chefe da revista. A seção de estudos é uma seção-coringa, em que publicamos artigos, ensaios, textos de formatos variados e sobre outros assuntos para além das questões da cena. Nossas conversas são como entrevistas, mas sem o viés jornalístico: procuramos estabelecer um diálogo mais espontâneo, menos objetivo do que se encontraria numa entrevista. $\mathrm{Na}$ seção de processos, publicamos textos escritos por artistas sobre o seu processo criativo, sobre um espetáculo, ou uma pesquisa especifica. Esta é a seção menos movimentada. É difícil conseguir textos de artistas que falem sobre os seus próprios trabalhos. E a seção de traduções reúne versões para o português de textos teóricos sobre teatro e crítica, bem como traduções de textos críticos de espetáculos brasileiros publicados originalmente em língua estrangeira, e até, eventualmente, traduções de peças curtas.
0 nosso quadro de colaboradores é formado por pesquisadores de teatro, principalmente. Embora alguns tenham formação em Jornalismo e escrevam regularmente para jornais, como Daniel Schenker, do Rio, e Luciana Romagnolli, curitibana residente em Belo Horizonte, os demais não têm passagem pelos jornais. Humberto Giancristofaro, sócio-colaborador, é da área de Filosofia, mas tem uma pesquisa sobre Antonin Artaud. Ele é editor do Selo Questão de Crítica, que publica edições impressas pela Editora Multifoco. A proposta do Selo é publicar monografias, textos de teatro e eventuais edições comemorativas. A Questão de crítica foi fundada por mim e por Dinah Cesare - nós duas somos da Teoria do Teatro, com pesquisas em Artes Visuais na pós-graduação. Os demais colaboradores regulares atuais, Dâmaris Grün, Mariana Barcelos, Pedro Allonso e Raphael Cassou, também fizeram a graduação em Teoria na UNIRIO, onde nos conhecemos e desenvolvemos o interesse pela crítica. Quase todos também estão envonlvidos com a criação artistica.

A proposta da revista é escrever crítica a partir de uma bagagem teórica, de pesquisa, e dar uma atenção às questões estéticas apresentadas pelos espetáculos que analisamos. Costumamos publicar fotos, preferencialmente fotos de cena, e procuramos indicar os sites e blogs dos grupos, para que os espectadores possam consultar a agenda daquele espetáculo, saber se a produção ainda está em cartaz no Rio ou se vai fazer turnê por outras cidades.

Recentemente, começamos a realizar eventos presenciais. $01^{\circ}$ Encontro Questão de Crítica, http://www.questaodecritica.com.br/encontro/, reuniu professores, artisitas, jornalistas e críticos para uma série
Daniele Avila Small é pesquisadora, critica e tradurtora de teatro. Mestranda em História Social da Cultura pela PUC-Rio, é graduada em Teoria do Teatro pela UNIRIO. É editora da Questão de critica e integra a comissão julgadora do Prêmio Questão de Crítica e do Prêmio APTR de Teatro Atualmente, é Diretora Artistica do Teatro Gláucio Gill, na Ocupação Complexo Duplo, com Felipe Vidal. 


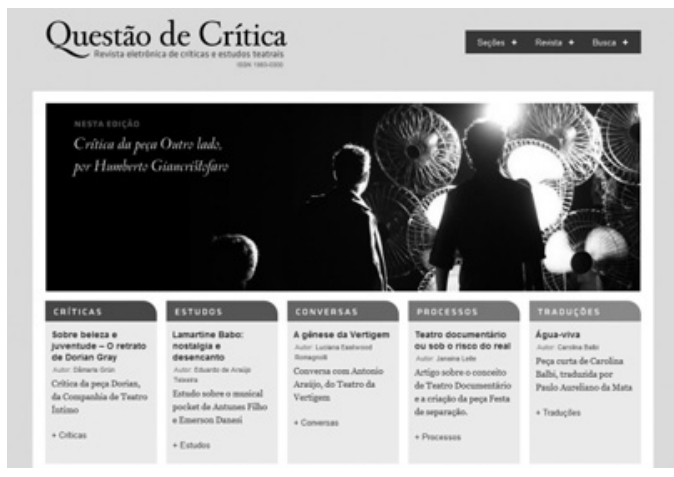

de debates, e ofereceu duas oficinas de crítica para estudantes de teatro. 0 10 Prêmio Questão de Crítica, http://questaodecritica.com.br/premioqdc/, é premiação para espetáculos em cartaz no Rio de Janeiro, para o qual podem concorrer espetáculos produzidos em qualquer cidade do Brasil - um ponto de diferença com relação às outras premiações que acontecem na cidade. Realizamos também um ciclo de debates chamado Encontro Pensamento, no Teatro Glaúcio Gill, em que Dâmaris Grün e Humberto Giancristofaro convidam profissionais de outras áreas de saber além do Teatro para conversar sobre um determinado espetáculo. 0 debate acontece com os artistas criadores, os debatedores convidados e um dos curadores.

Estes eventos foram importantes porque promoveram uma aproximação com os leitores da revista e contribuíram para consolidar a Questão de Crítica como um coletivo de críticos. Os debates do $1^{\circ}$ Encontro Questão de Crítica bem como alguns vídeos do Encontro Pensamento estão disponíveis no nosso canal no Vimeo, a TV Questão de Crítica, http://vimeo.com/questaodecritica, um desdobramento das nossas atividades, que estamos apenas começando a explorar.

Ainda é cedo para entendermos com clareza como a Internet está interferindo nas formas de produção e circulação de conteúdo sobre teatro na atualidade. Mas já podemos vislumbrar possibilidades de mudanças que parecem determinantes para a produção teatral contemporânea, bem como para a formação daqueles que iniciam neste momento histórico a sua aventura nas artes cênicas. 0 advento da Internet está ressignificando conceitos e práticas, mas não sabemos ainda em que medida isto se dá, tendo em vista que a vertiginosidade

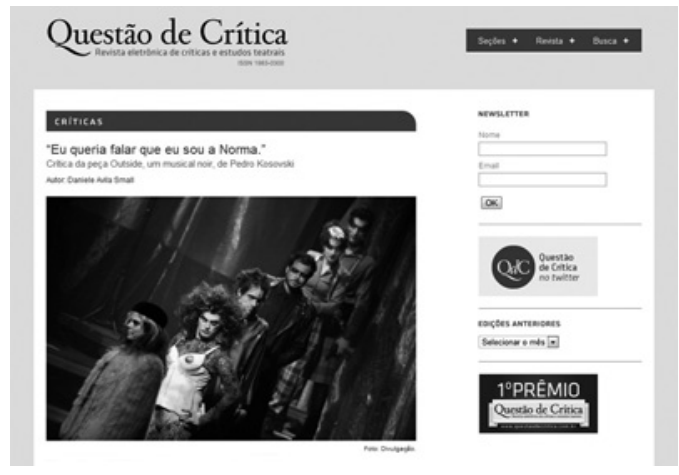

dos avanços tecnológicos nos dispositivos de comunicação não tem tanto efeito sobre as mentalidades regidas por outros esquemas de circulação de saberes. 0 que está em jogo nesse descompasso me parece ser uma questão de valores, de mecanismos de legitimação e de reconhecimento institucional que tanto interferem na situação da crítica de teatro.

Precisamos ainda do amadurecimento de algumas gerações para conseguirmos observar o que terá acontecido com o pensamento sobre a crítica no nosso tempo. Aqui no Rio, o paradigma da crítica jornalística ainda é muito forte. 0 entendimento que a classe artística parece ter sobre a atividade da crítica é muito atrelado ao modelo simplificado ditado pelos jornais de grande circulação.

A atividade da Questão de crítica ainda passa despercebida a uma parcela imensa do público de teatro da cidade - o que é até compreensível - mas passa também despercebida a uma porção igualmente significativa de artistas que atuam na cidade. 0 esfriamento da produção critica nos jornais cariocas nas últimas décadas provocou essa apatia na relação dos artistas e do público com a crítica. Os textos críticos passaram a ser interessantes apenas para aqueles que estão diretamente envolvidos nos espetáculos em questão, como mecanismo de divulgação e legitimação de seus trabalhos.

A forte presença da produção para televisão na cidade e a redução do jornalismo a uma grande e controladora organização são fatores importantes para uma análise do momento em que se encontra o teatro carioca. Existe um pensamento reinante de celebração do senso comum, legitimado por todos os lados, que parece muito difícil de quebrar. Se não fosse a Internet, acho que estaríamos vivendo num mundo das narrativas mais sombrias de Ray 
Bradbury, George Orwell e Aldous Huxley. Mas quanto mais a Internet ganha alcance, mais fascistas se tornam aqueles discursos dominantes. A Internet oferece a possibilidade de pulverização dos grandes discursos, de democratização do acesso a conteúdos diversos, e dá voz a quem quiser assumir a palavra, transferindo para o público, para o leitor ou espectador, a responsabilidade sobre as suas escolhas: o público passa a decidir o que quer ler e assistir. Isso apavora muita gente, que acredita que o público deve ser orientado por instâncias superiores nas suas escolhas. Orientar é muito diferente de formar e informar. A crítica predominante na capital carioca tem se esforçado demais para orientar o público, sem compromisso com a sua formação e nenhum interesse em se informar sequer a si mesma. É claro que existem exceções nesse contexto, mas são poucas e não têm espaço suficiente nos veículos de grande circulação. A questão crucial me parece ser a tomada de posição da classe artistica nesse quadro. Os velhos poderes ainda exercem sua sedução sobre artistas de qualquer idade, procedência ou formação. Os velhos sistemas de legitimação da crítica ainda usam a isca da possibilidade de catapultar algum indivíduo para a glória e o sucesso imediatos - acreditase. Por essa possibilidade, de perspectiva duvidosa, quase um jogo de azar, descarta-se qualquer tentativa de mobilização de classe. Todo pensamento rui diante da promessa, mesmo que distante, de um superlativo estrondoso na página de um jornal que a sua família leia.

Quando o assunto é a crítica, o fio condutor do pensamento é a vaidade. Os artistas querem um lugar ao sol daquele velho mundo, que ainda se organiza de acordo com as premissas da crítica, da historiografia e da noção de sucesso que enquadra o universo das artes num esquema de enaltecimento exacerbado de grandes nomes, de individuos intocáveis, divas, gênios.

0 lugar do crítico famoso, temido e poderoso ainda existe por aqui, mas está preso por um fio. É uma questão de tempo: em breve, esse lugar, o lugar do único, não vai mais existir. Mas com essa mudança, outras também se dão. 0 lugar da diva e do gênio também está comprometido. 0 que não significa que a competência e a seriedade não terão reconhecimento. Pelo contrário, talvez. Na atividade constante da crítica hoje, vejo excelentes trabalhos mais do que grandes sucessos, artistas com carreiras sólidas correndo riscos e experimentando mudanças mais do que gênios estabelecidos na decrepitude dos seus pedestais. (Isso existe, tem público, tem atenção da mídia, tem recursos, mas perde espaço a olhos vistos.) 0 mesmo diretor que fez um espetáculo incrivel no ano passado faz um trabalho desastroso nesse ano. E nem por isso está liquidado. A crítica na Internet, por não falar mais daquele lugar de poder que o jornal carrega, não eleva ninguém às alturas, mas também não destrói nada, não "tira espetáculo de cartaz", como dizem. Isso é bom. A crítica na Internet não tem nada a ver com poder, mas com possibilidade. Um texto circula na Internet de acordo com a sua relevância intrínseca e sua comunicabilidade. Ele não tem sua distribuição garantida a priori, ou seja, só ganha leitores se tiver mérito próprio. Isso é muito bom.

0 ruim é que numa cidade como o Rio, cada vez mais turística, cada vez mais regida pela lógica do "por fora, bela viola, por dentro, pão bolorento", e num pais como o Brasil, tão vasto, tão dificil de cuidar, de formar e informar, com uma atual Ministra da Cultura que não sabe do que se trata quando o assunto é a Internet, o discurso dominante é de puro retrocesso. Os dinossauros, 
gênios e divas do teatro desconhecem o fenômeno de compartilhamento de conteúdo na rede e não se interessam em ler o que os anônimos online pensam e escrevem sobre o que eles fazem e representam. Estamos entre dois mundos que ficaram muito diferentes numa velocidade impressionante. Quanto mais as fronteiras caem, mais se estabelecem os abismos.

Uma das nossas principais motivações para a criação da revista era o desejo de estabelecer pontes entre o que se chama "a teoria" e "a prática" (que nunca de fato entendemos como instâncias separadas), entre o mundo acadêmico em que nos víamos de algum modo inseridos e o universo da realização de espetáculos, do qual estávamos igualmente próximos. Depois, foi possivel perceber que, mesmo se não houvesse esse folclore todo em torno dessa dicotomia, estaríamos sempre construindo pontes. A atividade da critica parece ser isso mesmo: 0 movimento de criar uma materialidade (um texto) que colabore para o trânsito (uma conversa) entre dois lugares (o do artista e o do espectador). Recentemente, reparamos que a Internet altera nossa noção de presença e nos aproxima de fato da produção artística de outras cidades do Brasil. Isso nos distancia sobremaneira de alguns velhos hábitos da crítica teatral carioca: o bairrismo, 0 protecionismo político e a competitividade pueril entre as capitais brasileiras das regiões Sul e Sudeste. E vamos descobrindo que a tal ponte entre a teoria e a prática é uma bobagem, porque ela sempre esteve ali, é só olhar com atenção.

0 que é difícil mesmo é ser a geração-cobaia da passagem entre duas eras que coabitam o nosso momento histórico, um tempo partido por este imenso divisor de águas - a revolução digital.

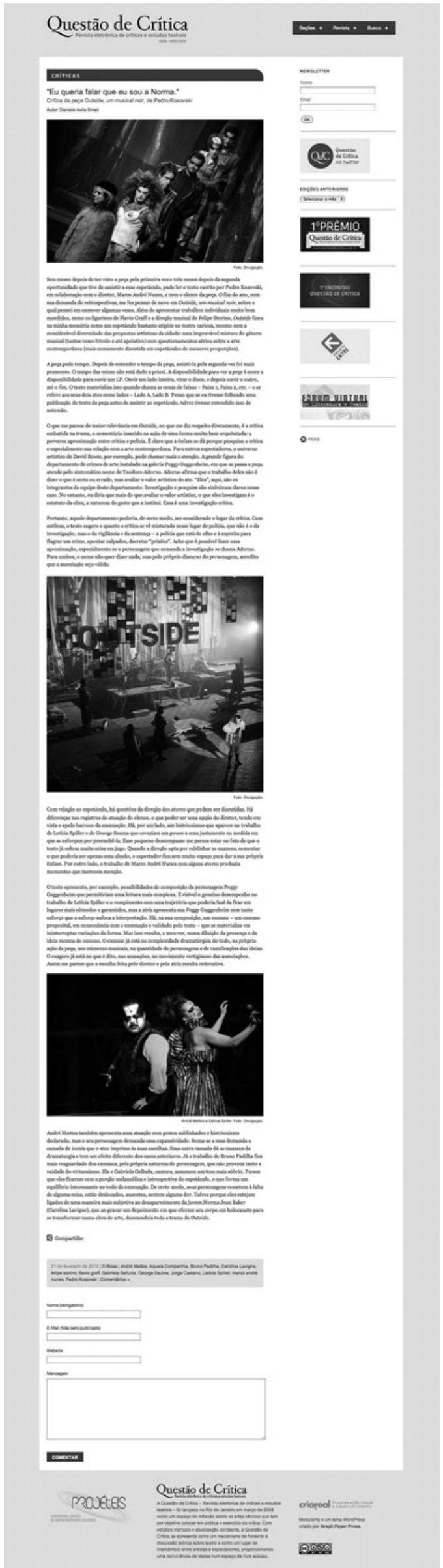

